\title{
Analisis Penjadwalan Produksi Dengan Metode Campbell Dudek Smith (CDS), PT. ISM TBK. Divisi Bogasari Flour Mills Jakarta
}

\author{
Purwati $^{1}$, Santika Sari ${ }^{1}$ \\ ${ }^{1}$ Teknik Industri, Universitas Pembangunan Nasional Veteran Jakarta \\ email : ppurwati997@gmail.com \\ doi: https://doi.org/10.31315/opsi.v13i2.3674
}

Received: $13^{\text {th }}$ August 2020; Revised: 23 ${ }^{\text {rd }}$ September 2020; Accepted: $29^{\text {th }}$ September 2020;

Available online: $22^{\text {nd }}$ December 2020; Published regularly: December 2020

\begin{abstract}
Bogasari is one of the largest wheat flour companies in Indonesia, besides wheat flour also produces a product namely pasta, pellet, and livestock food. As a large company that produces many products need to do production scheduling so that the production time and product quantity produced reach the maximum. To avoid the extension of the production completion time that can ultimately lower the production quantity, one of the strategies that the company can do is by scheduling and allocating the company's resources. The selection of the right scheduling method needs to be done so that the company can have a decision in production scheduling that results in a minimum production completion time and the demand can be fulfilled on time. The methods used are CDS (Campbell Dudek Smith), SPT (Shortest Processing Time), LPT (Longest Processing Time), EDD (Earliest Due Date), and FCFS (First Come First Served). From the results of the research conducted the best scheduling method is the CDS with a makespan of 2,576,807.5 minutes and a flowtime of 21,665,932 minutes.
\end{abstract}

Keywords: scheduling; CDS; SPT; LPT; EDD; FCFS

\begin{abstract}
ABSTRAK
Bogasari merupakan salah satu perusahaan tepung terigu yang terbesar di Indonesia, selain tepung terigu Bogasari juga menghasilkan produk sampingan yaitu pasta, pellet, dan makanan ternak. Sebagai perusahaan besar yang menghasilkan banyak produk perlu dilakukannya penjadwalan produksi sehingga waktu produksi dan kuantitas produk yang dihasilkan mencapai maksimal. Untuk menghindarai perpanjangan waktu penyelesaian produksi yang pada akhirnya dapat menurunkan kuantitas produksi, salah satu strategi yang dapat dilakukan perusahaan adalah dengan penjadwalan dan pengalokasian sumber daya perusahaan. Pemilihan metode penjadwalan yang tepat perlu dilakukan sehingga perusahaan dapat memiliki keputusan yang terpat dalam penjadwalan produksi yang menyebabkan waktu penyelesaian produksi yang minimum dan permintaan dapat terpenuhi tepat waktu. Metode yang digunakan adalah CDS (Campbell dudek Smith), SPT (Shortest Processing Time), LPT (Longest Processing Time), EDD (Earliest Due Date), dan FCFS (First Come First Served). Dari hasil penelitian yang dilakukan metode penjadwalan terbaik adalah CDS dengan makespan sebesar 2,576,807.5 menit dan flowtime 21,665,932 menit.
\end{abstract}

Kata Kunci: Penjadwalan; CDS ;SPT; LPT; EDD; FCFS.

\section{PENDAHULUAN}

Penjadwalan merupakan bagian penting dari proses produksi, hal ini disebabkan karena sebelum dilakukannya kegiatan produksi di lantai produksi perlu dibuat penjadwalan produksi agar produk yang dihasilkan sesuai permintaan dan terpenuhi tepat pada waktu yang ditentukan. Produksi itu sendiri adalah keseluruhan proses yang dilakukan untuk menghasilkan produk atau jasa. Penjadwalan dapat diartikan sebagai pengalokasian sejumlah sumber daya untuk melakukan sejumlah tugas atau operasi dalam jangka waktu tertentu dan merupakan proses pengambilan keputusan yang memiliki peran penting pada industri manufaktur (Baker \& Trietsch, 2009). Salah satu masalah yang dihadapi pada sistem produksi adalah melakukan pengaturan penjadwalan produksi agar target yang diinginkan terpenuhi dan tepat pada waktunya. Jika sistem penjadwalan yang digunakan kurang baik atau tepat maka dapat menyebabkan memperpanjang waktu penyelesaian produk dan akhirnya dapat menurunkan kuantitas produk yang dihasilkan 
dan permintaan konsumen pun tidak dapat terpenuhi.

penjadwalan produksi merupakan salah satu cara untuk mengalokasikan sumber daya produksi (material, mesin, dan operator) yang tersedia, untuk menentukan waktu dimulainya operasi dan kapan operasi tersebut harus selesai dalam mengerjakan sejumlah pekerjaan (job) (Heizer \& Render, 1996).

Penjadwalan didefinisikan sebagi proses pengaturan waktu dari suatu kegiatan operasi. Penjadwalan disusun dengan berbagai pertimbangan dan keterbatasan yang ada (Herjanto, 1999).

Penjadwalan memiliki tujuan yaitu meningkatkan penggunaan sumber daya untuk meminimalkan waktu proses dan meningkatkan produktivitas, mengurangi persediaan barang setengah jadi atau mengurangi beberapa pekerjaan yang menunggu, mengurangi keterlambatan, dan membantu dalam pengambilan keputusan mengenai perencanaan kapasitas yang dibutuhkan (Arifin dan Rudyanto, 2010).

Dalam industri manufaktur, penjadwalan memegang peranan penting dalam penentuan penggunaan mesin dalam suatu produksi. Dengan jumlah mesin dan pekerja yang terbatas, perusahaan harus dapat mengambil keputusan yang tepat mengenai pekerjaan yang mana yang harus diselesaikan terlebih dahulu. Penjadwalan dilakukan dengan tujuan agar produk dapat diselesaikan tepat waktu sesuai dengan spesifikasi yang telah ditetapkan, memaksimalkan produktivitas, meminimumkan waktu penyelesaian produksi, meningkatkan penggunaan mesin, serta mengurangi persediaan barang dalam proses.

Penjadwalan memiliki fungsi yang secara umum digunakan untuk mengefektifkan dan mengefisienkan penggunaan sumber daya (Kusuma, 2009). Penjdawalan diklasifikasikan menjadi dua yaitu penjadwalan mesin tunggal dan penjadwalan paralel (Pinedo, 2012).

Penelitian terhadap penjadwalan juga pernah dilakukan menggunakan metode CDS dan menghasilkan nilai makespan sebesar 52 hari dan tidak ada pesanan yang terlambat (Ervil \& Nurmayuni, 2018)

Sehingga pada penelitian ini dilakukan perbandingan metode penjadwalan untuk memilih metode penjadwalan terbaik yang dapat digunakan pada produksi tepung terigu khususnya pada wilayah 3 mill IJ.

\section{METODE}

Penelitian ini dilakukan pada perusahaan PT. ISM Tbk, Divisi Bogasari Flour Mills khususnya pada Departemen Mill wilayah 3 yaitu Mill IJ dengan job adalah tepung yang akan diproduksi pada bulan Agustus - September 2019. Penjadwalan memiliki pengaturan pekerjaan. Penelitian dilakukan dengan membandingkan beberapa metode yaitu:

2.1 Metode FCFS (First Come First Served), pada metode ini setiap proses yang siap yang akan didahulukan dari yang lain tanpa mempertimbangkan kriteria lainnya.

2.2 Metode SPT (Shortest Processing Time), yaitu metode yang memprioritaskan pekerjaan berdasarkan waktu proses yang paling pendek. Aturan ini secara umum meningkatkan efisiensi dan mempunyai dampak pada aliran kas perusahaan. Karena secara matematis dapat dibuktikan bahwa SPT dapat meminimasi rata - rata waktu penyelesaian. Meminimasi flow time mempunyai dampak yang positif terhadap pencapaian batas waktu pekerjaan selesai (Hanna dan Newman, 2001).

2.3 Metode LPT (Longest Processing Time), yaitu metode yang berkebalikan dari SPT dengan memprioritaskan proses yang memiliki waktu lebih panjang terlebih dahulu.

2.4 Metode EDD (Earliest Due Date), yaitu metode yang dilakukan dengan cara perhitungan waktu proses, aliran waktu, tanggal jatuh tempo yang kemudian diurutkan nilai waktu proses dari terkecil hingga terbesar, dan keterlambatannya. Due date (batas waktu penyerahan) sama dengan deadline untuk sebuah tugas yang mempertimbangkan batas waktu penyerahan. Penalti akan terjadi apabila keterlambatan terjadi (Bedworth, 1987).

2.5 Metode CDS (Campbell Dudek Smith), Metode ini pada dasarnya memecahkan persoalan $n$ job pada $m$ mesin flow shop ke dalam dua grup, kemudian pengurutan job pada kedua mesin tadi menggunakan algoritma Johnson. Setelah diperoleh sebanyak m-1 alternatif urutan job, kemudian dipilih urutan dengan nilai meke span terkecil. Setiap pengerjaan atau job 
yang akan diselesaikan harus melewati proses pada masing-masing mesin. Pada penjadwalan ini diusahakan untuk mendapatkan harga make span yang terkecil dari $(\mathrm{m}-1)$ kemungkinan penjadwalan. Penjadwalan dengan harga mekespan terkecil merupakan urutan pengerjaan job yang tidak baik.

Dari hasil nilai makespan dan flowtime yang dihasilkan dari setiap metode, lalu dipilih nilai yang terkecil dan itu merupakan sistem penjadwalan terbaik.

\section{HASIL DAN PEMBAHASAN}

Berikut merupakan hasil dan pembahasan yang diperoleh dari setiap metode.

3.1 Metode FCFS (First Come First Served) yaitu, dengan mengurutkan pekerjaan yang siap terlebih dahulu. Berikut adalah hasil dari perhitungan yang dilakukan.

Tabel 1. Hasil Perhitungan FCFS

\begin{tabular}{cccl}
\hline Job & $\begin{array}{c}\text { Waktu } \\
\text { Proses } \\
\text { (menit) }\end{array}$ & $\begin{array}{c}\text { Waktu } \\
\text { Kumulatif } \\
\text { (menit) }\end{array}$ & \multicolumn{1}{c}{$\begin{array}{c}\text { Tanggal } \\
\text { Jatuh }\end{array}$} \\
\hline $\mathbf{1}$ & 1876679.64 & 1876679.64 & 28 juli - 4 ags \\
$\mathbf{2}$ & 1618572.78 & 3495252.42 & $4-11$ ags \\
$\mathbf{3}$ & 1236062.52 & 4731314.94 & $11-18$ ags \\
$\mathbf{4}$ & 2455215.84 & 7186530.78 & $18-25$ ags \\
$\mathbf{5}$ & 1151999.64 & 8338530.42 & 25 ags - 1 sept \\
$\mathbf{6}$ & 1558665.90 & 9897196.32 & $1-8$ sept \\
$\mathbf{7}$ & 2017388.34 & 11914584.66 & $8-15$ sept \\
$\mathbf{8}$ & 2064250.98 & 13978835.64 & $15-22$ sept \\
$\mathbf{9}$ & 1949630.76 & 15928466.4 & $22-29$ sept \\
Total & & 77347391.22 & \\
\hline
\end{tabular}

Dari tabel di atas dapat diketahui bahwa urutan pekerjaan yaitu $1-2-3-4-5-6$ $-7-8-9$ dengan makespan yaitu $12,928,466.4$ menit dan flowtime dari seluruh proses produksi sebesar $77,347,391.22$ menit.

\subsection{Metode SPT (Shortest Processing Time)}

Yaitu dengan mengurutkan dari proses yang memiliki waktu terkecil terlebih dahulu, berikut adalah hasil perhitungan yang diperoleh.
Tabel 2. Hasil Perhitungan SPT

\begin{tabular}{cccl}
\hline Job & $\begin{array}{c}\text { Waktu } \\
\text { Proses } \\
\text { (menit) }\end{array}$ & $\begin{array}{c}\text { Waktu } \\
\text { Kumulatif } \\
\text { (menit) }\end{array}$ & $\begin{array}{c}\text { Tanggal } \\
\text { Jatuh }\end{array}$ \\
\hline $\mathbf{5}$ & 1151999.64 & 1151999.64 & 25 ags - 1 sept \\
$\mathbf{3}$ & 1236062.52 & 2388062.16 & $11-18$ ags \\
$\mathbf{6}$ & 1558665.90 & 3946728.06 & $1-8$ sept \\
$\mathbf{2}$ & 1618572.78 & 5565300.84 & $4-11$ ags \\
$\mathbf{1}$ & 1876679.64 & 7441980.48 & 28 juli - 4 ags \\
$\mathbf{9}$ & 1949630.76 & 9391611.24 & $22-29 \mathrm{sept}$ \\
$\mathbf{7}$ & 2017388.34 & 11408999.58 & $8-15 \mathrm{sept}$ \\
$\mathbf{8}$ & 2064250.98 & 13473250.56 & $15-22 \mathrm{sept}$ \\
$\mathbf{4}$ & 2455215.84 & 15928466.40 & $18-25 \mathrm{ags}$ \\
Total & & 70696398.96 & \\
\hline
\end{tabular}

Dari tabel di atas dapat diketahui bahwa urutan pekerjaan yaitu $5-3-6-2-1-9-7-$ $8-4$ dengan makespan yaitu 15,928,466.40 menit dan flowtime dari seluruh proses produksi sebesar 70,696,398.96 menit.

\subsection{Metode LPT (Longest Processing Time)}

Yaitu dengan mengurutkan pekerjaan yang memiliki waktu proses terbanyak terlebih dahulu, berikut adalah hasil perhitungan yang dilakukan.

Tabel 3. Hasil Perhitungan LPT

\begin{tabular}{cccl}
\hline Job & $\begin{array}{c}\text { Waktu } \\
\text { Proses } \\
\text { (menit) }\end{array}$ & $\begin{array}{c}\text { Waktu } \\
\text { Kumulatif } \\
\text { (menit) }\end{array}$ & $\begin{array}{c}\text { Tanggal } \\
\text { Jatuh }\end{array}$ \\
\hline $\mathbf{4}$ & 2455215.84 & 2455215.84 & $18-25 \mathrm{ags}$ \\
$\mathbf{8}$ & 2064250.98 & 4519466.82 & $15-22 \mathrm{sept}$ \\
$\mathbf{7}$ & 2017388.34 & 6536855.16 & $8-15 \mathrm{sept}$ \\
$\mathbf{9}$ & 1949630.76 & 8486485.92 & $22-29 \mathrm{sept}$ \\
$\mathbf{1}$ & 1876679.64 & 10363165.56 & 28 juli - 4 ags \\
$\mathbf{2}$ & 1618572.78 & 11981738.34 & $4-11 \mathrm{ags}$ \\
$\mathbf{6}$ & 1558665.90 & 13540404.24 & $1-8$ sept \\
$\mathbf{3}$ & 1236062.52 & 14776466.76 & $11-18 \mathrm{ags}$ \\
$\mathbf{5}$ & 1151999.64 & 15928466.4 & $25 \mathrm{ags}-1$ \\
& & & sept \\
Jumlah & 88588265.04 & \\
\hline
\end{tabular}

Dari tabel di atas dapat diketahui bahwa urutan pekerjaan yaitu $4-8-7-9-1-2$ - $6-3-5$ dengan makespan yaitu $15,928,466.40$ menit dan flowtime dari seluruh proses produksi sebesar $88,588,265.04$ menit.

\subsection{Metode EDD (Earliest Due Date)}

Yaitu dengan memprioritaskan pekerjaan dengan tanggal jatuh tempo yang terlebih dahulu, berikut adalah hasil perhitungan. 
Tabel 4. Hasil Perhitungan EDD

\begin{tabular}{cccl}
\hline Job & $\begin{array}{c}\text { Waktu } \\
\text { Proses } \\
\text { (menit) }\end{array}$ & $\begin{array}{c}\text { Waktu } \\
\text { Kumulatif } \\
\text { (menit) }\end{array}$ & $\begin{array}{c}\text { Tanggal } \\
\text { Jatuh }\end{array}$ \\
\hline $\mathbf{1}$ & 1876679.64 & 1876679.64 & 28 juli -4 ags \\
$\mathbf{2}$ & 1618572.78 & 3495252.42 & $4-11$ ags \\
$\mathbf{3}$ & 1236062.52 & 4731314.94 & $11-18$ ags \\
$\mathbf{4}$ & 2455215.84 & 7186530.78 & $18-25$ ags \\
$\mathbf{5}$ & 1151999.64 & 8338530.42 & 25 ags - 1 sept \\
$\mathbf{6}$ & 1558665.90 & 9897196.32 & $1-8$ sept \\
$\mathbf{7}$ & 2017388.34 & 11914584.66 & $8-15$ sept \\
$\mathbf{8}$ & 2064250.98 & 13978835.64 & $15-22$ sept \\
$\mathbf{9}$ & 1949630.76 & 15928466.4 & $22-29$ sept \\
Total & & 77347391.22 & \\
\hline
\end{tabular}

Dari tabel di atas dapat diketahui bahwa urutan pekerjaan yaitu $1-2-3-4-5-6$ $-7-8-9$ dengan makespan yaitu $12,928,466.4$ menit dan flowtime dari seluruh proses produksi sebesar $77,347,391.22$ menit.

\subsection{Metode CDS (Campbell Dudek Smith)}

Metode ini merupakan salah satu metode penjadwalan produksi yang dapat meminimasi makespan dan menghasilkan solusi yang mendekati optimal (Ginting, 2009). Pada perhitungannya dilakukan kombinasi stasiun kerja menjadi 2 kelompok. Pada perhitungan dilakukan iterasi pengurutan sebanyak 24 kali (SK 1). Bila waktu proses terkecil terletak dimesin pertama, job tersebut diletakan diurutan depan, sedangkan bila waktu proses terkecil terletak di mesin kedua maka diletakan diurutan belakang. Berikut adalah hasil perhitungan metode CDS:

Tabel 5. Perhitungan iterasi 1 Model CDS

\begin{tabular}{ccc}
\hline \multirow{2}{*}{ Job } & \multicolumn{2}{c}{ Mesin } \\
\cline { 2 - 3 } $\mathbf{1}$ & M1 (menit) & M2 (menit) \\
$\mathbf{2}$ & 16936.4 & 37291.20 \\
$\mathbf{3}$ & 14607.1 & 32162.40 \\
$\mathbf{4}$ & 11155.1 & 24561.60 \\
$\mathbf{5}$ & 22157.5 & 48787.20 \\
$\mathbf{6}$ & 10396.4 & 22891.20 \\
$\mathbf{7}$ & 14066.5 & 30972.00 \\
$\mathbf{8}$ & 18206.3 & 40087.20 \\
$\mathbf{9}$ & 18629.2 & 41018.40 \\
\hline
\end{tabular}

Dari tabel tersebut urutan pekerjaan yang digunakan adalah 5-3-6-2-1-9-7$8-4$, selanjutnya dilakukan perhitungan terhadap makespan dan juga flowtime. Rekapitulasi hasil dari perhitungan CDS dapat dilihat pada Tabel 6 .
Tabel 6. Rekapitulasi CDS

\begin{tabular}{cccc}
\hline Iterasi & $\begin{array}{c}\text { Urutan } \\
\text { Job }\end{array}$ & Makespan & Flowtime \\
\hline $\mathbf{1}$ & $5-3-$ & & \\
$\cdot$ & $6-2-$ & $2,576,807.5$ & $21,665,932$ \\
$\cdot$ & $1-9-$ & menit & menit \\
$\dot{\boldsymbol{j}}$ & $7-8-$ & & \\
\hline
\end{tabular}

Dari tabel $\mathrm{d}$ atas dapat diketahui bahwa urutan pekerjaan yaitu $5-3-6-2-1-9$ - $7-8-4$ dengan makespan yaitu 2,576,807.5 menit dan flowtime dari seluruh proses produksi sebesar $21,665,932$ menit.

\subsection{Perbandingan Metode}

Selanjutnya dilakukan perbandingan terhadap nilai makespan dan flowtime dari setiap metode dan dilakukan pemilihan terhadap metode peramalan terbaik dengan nilai makespan dan flowtime terkecil.

Tabel 8. Perbandingan Metode

\begin{tabular}{cll}
\hline Metode & Makespan & Flowtime \\
\hline FCFS & $15,928,466.4$ & $77,347,391.22$ \\
SPT & $15,928,466.4$ & $70,696,398.96$ \\
LPT & $15,928,466.4$ & $88,588,265.04$ \\
EDD & $15,928,466.4$ & $77,347,391.22$ \\
CDS & $2,576,807.5$ & $21,665,932$ \\
\hline
\end{tabular}

Berdasarkan tabel dapat diketahui bahwa metode terbaik untuk penjadwalan produksi ini adalah metode CDS (Campbell Dudek Smith) dengan urutan pekerjaan yaitu 5-3-6-2-1-9-7-8-4 dengan makespan yaitu $2,576,807.5$ menit dan flowtime dari seluruh proses produksi sebesar 21,665,932 menit.

\section{KESIMPULAN}

Berdasarkan penelitian yang dilakukan, metode terbaik untuk penjadwalan produksi tepung terigu pada Bogasari Flour Mill Wilayah 3 Mill IJ adalah metode CDS (Campbell Dudek Smith), yaitu dengan dengan urutan pekerjaan yaitu $5-3-6-2-1-9-7-8-4$ dengan makespan yaitu 2,576,807.5 menit dan flowtime dari seluruh proses produksi sebesar 21,665,932 menit.

Untuk penelitian selanjutya diharapkan dapat melakukan lebih banyak iterasi terhadap metode CDS. 


\section{DAFTAR PUSTAKA}

Baker, K.R., \& Trietsch, D. (2009). Principles Of Sequencing And Scheduling. New Jersey: John Wiley \& Sons.

Ervil, R., \& Nurmayuni, D,. (2018). Penjadwalan Produksi Dengan Metode Campbell Dudej Smith (CDS) Untuk Meminimumkan Total Waktu Produksi (Makespan). Jurnal Sains dan Teknologi: Jurnal Keilmuan dan Aplikasi Teknologi Industri. Vol. 18 no. 2, pp $97-101$.

Ginting, R. (2009). Penjadwalan Mesin. Yogyakarta: Graha Ilmu

Hanna, M.D., \& Newman, W.R., (2001). Operation Management: An Integrated Approach. Prentice Hall, Inc., New Jersey.

Bedworth, D.D., (1987), Integrated Production, Control System: Management, Analysis, and Design. Wiley., US.

Kusuma, Hendra, (2009), Manajemen Produksi Perencanaan dan Pengendalian Produksi, CV. Andi Offset, Yogyakarta.

Heizer, J., \& Render, B., (1996). Production and Operations Management: Strategic and Tactical Decisions. Prentice Hall., New Jersey.

Pinedo, M. L., (2012). Scheduling: Theory, Algorithms, and System $4^{\text {th }}$ Edition. Springer, New Jersey.

Arifin \& Rudyanto, A., (2010). Perencanaan Sistem Informasi Penjadwalan Produksi Paving Black Pada CV. Eko Joyo. Seminar Nasional Aplikasi Teknologi Informasi, Yogyakarta.

Herjanto, E., (1999). Manajemen Produksi dan Operasi. PT. Gramedia Widiasarana Indonesia, Jakarta. 